\title{
South African Pecan Planting Boom and Carbon Sequestration in Biomass
}

\section{Cornelius Arnoldus Pieterse*}

GWK Pecans, South Africa

*Corresponding Author: Cornelius Arnoldus Pieterse, GWK Pecans, South Africa.

DOI: $10.31080 /$ ASAG.2020.04.0787
Received: January 21, 2020

Published: January 30, 2020

(C) All rights are reserved by Cornelius

Arnoldus Pieterse.

\begin{abstract}
The Pecan tree (Carya illinoinensis) is one of the most planted trees per year in South Africa, since 2012. According to SAPPA (South African Pecan Producers Association) an average of 3,513,000 trees per year were planted, from 2010 to 2018. This boom in growing pecan trees, could have an enormous impact on carbon sequestration within living and productive biomass, which delivers environmental impacting functions and services. According to current data it appears that South African Pecan Producers are going to be sequestering $\approx 3477$ megatons/year of biomass on average for 8 years' time. In the total 8 years sequestering $\approx 27816$ megatons of biomass. But proper management of irrigation and fertilization will be needed to combat the excessive and ineffective emissions of $\mathrm{CO}_{2}, \mathrm{CH}_{4}$, and $\mathrm{N}_{2} \mathrm{O}$ greenhouse gasses in the pecan agriculture production industry.

Keywords: Carbon; Biomass; Pecan Orchards
\end{abstract}

Pecan orchards could readily provide global municipal environmental functions and services from a watershed point of view. Since, according to Hartman., et al. [1] the following benefits of trees to a community were identified:

- Supply oxygen

- Sequester carbon dioxide

- Reduce noise pollution

- Trap particulates

- Alter microclimate

- Improve aesthetics

- Enhance outdoor urban spaces

- Alter the community's character.

These benefits are non-commensurable according to Mexal [2]. While these services are a benefit to all in the surrounding area. But since it is difficult to trade, some focus seems to be lost from

\begin{tabular}{|l|c|c|c|c|c|c|c|}
\hline Parameter & Trunk & Branches & Leave & Husks & Pecans & Roots & Total \\
\hline $\mathrm{kg} /$ tree & 263 & 541 & 64 & 10 & 28 & 362 & 1268 \\
\hline $\mathrm{kg} /$ tree/yr & 17 & 36 & 64 & 10 & 28 & 24 & 179 \\
\hline
\end{tabular}

Table 1: Estimated biomass partitioning of mature pecan trees (Kraimer, unpublished).

these benefits. Using Mexal's data in Table 1 it was possible to calculate carbon sequestration in South African pecan orchards:

Assuming that there is no alternate bearing and severe drought, we can use these and the SAPPA data for how many trees has been planted from 2010 to 2018 to determine the amount of biomass in ton/ha/year each tree would produce for each year the amount of average pecan trees were planted. Estimating an percentage of tree loss it is possible to determine carbon sequestration in five senario's.

\begin{tabular}{|c|c|c|c|c|c|c|c|c|}
\hline \multicolumn{8}{|c|}{ Biomass that could be produced in South Africa every year from 2026 - 2033 by the Pecan Nut Industry (ton/tree/yr) } \\
\hline \% Tree Loss & Avg Trees planted/yr & Trunk & Branches & Leaves & Husks & Pecans & Roots & Total \\
\hline $10 \%$ & 351300 & 5972 & 12647 & 22483 & 3513 & 9836 & 8431 & 62883 \\
\hline $25 \%$ & 292750 & 4977 & 10539 & 18736 & 2928 & 8197 & 7026 & 52402 \\
\hline $50 \%$ & 195167 & 3318 & 7026 & 12491 & 1952 & 5465 & 4684 & 34935 \\
\hline $75 \%$ & 97583 & 1659 & 3513 & 6245 & 976 & 2732 & 2342 & 17467 \\
\hline $90 \%$ & 39033 & 664 & 1405 & 2498 & 390 & 1093 & 937 & 6987 \\
\hline
\end{tabular}

\section{Table 2}

All this biomass is created by the simple organic chemistry of photosynthesis, which plants do so effectively. (See Figure 2). As much of this biomass needs to remain on the land and in the pecan orchard to supply enough organic matter that will be able to provide food for all the different micro-organisms in the soil.
As Jones says in her [3] Australian Farm Journal, that all plants go through the exact same cycle of sequestrating carbon. Whether a tree, grain grasses, pasture, or weeds, all photosynthesise and effectively produce sugars we can measure, represented by BRIX. Some of these sugars are exuded by the root into the rhizosphere, 


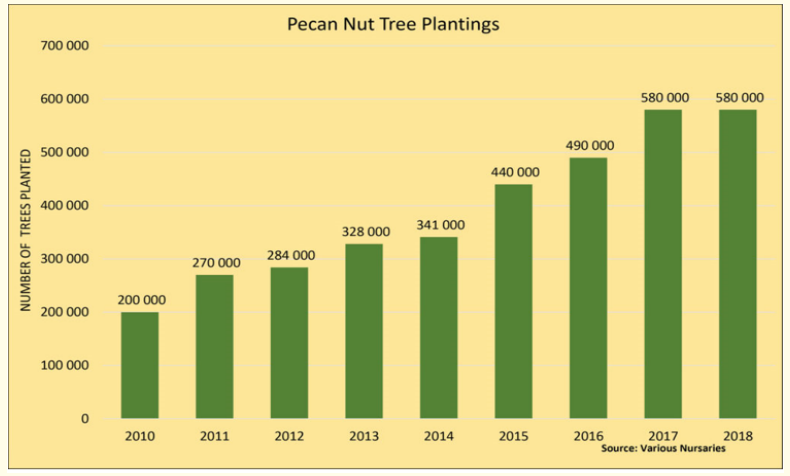

Figure 1: Pecan Nut Tree Plantings from 2010-2018. SAPPA website: https://www.sappa.za.org/industry-statistics/.

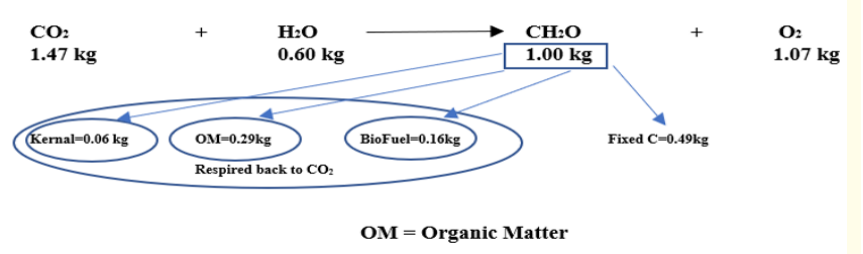

Figure 2: Basic photosynthetic reaction and relative partitioning of fixed carbon. attracting specific microbes for a specific task. The microbes trade resources such as protection from pathogens or parasites, hormones to stimulate growth and mineralize nutrients. All of which increases root volume which will influence growth or fruiting. This resource trading requires $\mathrm{CO}_{2}$, and calculated from photosynthetic reactions within pecans, we can suggest another way of calculating the $\mathrm{CO}_{2}$ sequestration - according to the photosynthetic reaction.

In Figure 2: Basic photosynthetic reaction and relative partitioning of fixed carbon, Maxel shows that $1.47 \mathrm{~kg}$ of $\mathrm{CO}_{2}$ and $0.6 \mathrm{~kg}$ of water reacts under sunlight in pecan trees to give $1 \mathrm{~kg}$ of $\mathrm{CH}_{2} \mathrm{O}$ and $1.07 \mathrm{~kg}$ of $\mathrm{O}_{2}$. Of the $1 \mathrm{~kg} \mathrm{CH}_{2} \mathrm{O}, 0.06 \mathrm{~kg}$ resides in the kernel, $0.29 \mathrm{~kg}$ is used as organic matter (OM) and $0.16 \mathrm{~kg}$ is used to create biofuel. The $0,49 \mathrm{~kg}$ that remains is fixed C. Thus only $49 \%$ of the $\mathrm{CO}_{2}$ will remain stable in the tree. If this is truly the case in practise, South Africa could be looking at between 3,563 tons/tree/year and 32070 tons/tree/year of $\mathrm{CO}_{2}$ safely captured in biomass for the trees planted from 2014 to 2018.

From this estimated amount of $\mathrm{CO}_{2}$ that could be captured from the atmosphere soil organic matter can be built, while stimulating microbe populations in the soil. Further losses of $\mathrm{CO}_{2}$ due to management practises will still need to be identified and calculated to make sure there is no unnecessary or wasteful loss.

\begin{tabular}{|c|c|c|c|c|}
\hline \multicolumn{5}{|c|}{$\mathbf{C O}_{\mathbf{2}}$ Sequestrated/yr for the average tree planted between 2011 to 2018} \\
\hline \% Tree Loss & $\begin{array}{c}\text { Avg Trees planted for 8 } \\
\text { years with loss deducted }\end{array}$ & $\begin{array}{c}\text { Total Biomass } \\
\text { (ton/tree/yr) }\end{array}$ & $\begin{array}{c}\mathbf{C O}_{2} \text { Sequestrated } \\
\text { (ton/tree/year) }\end{array}$ & $\begin{array}{c}\text { Co }_{\mathbf{2}} \text { Sequestrated for the avg trees } \\
\text { in SA over one year (megaton/yr) }\end{array}$ \\
\hline 10 & 351,300 & 62,883 & 32,070 & 11,266 \\
\hline 25 & 292,750 & 52,402 & 26,725 & 7,823 \\
\hline 50 & 195,167 & 34,935 & 17,817 & 3,477 \\
\hline 75 & 97,583 & 17,467 & 8,908 & 869 \\
\hline 90 & 39,033 & 6,987 & 3,563 & 139 \\
\hline
\end{tabular}

\section{Table 3}

From a consumers' vantage point, one can also calculate the amount of $\mathrm{CO}_{2}$ sequestered inside of the pecan kernels as well. This could be an incentive for consumers to buy more pecan nuts.

Maxel further stated that "...for every unit of carbohydrate created by the pecan tree, almost 1.5 units of carbon dioxide $\left(\mathrm{CO}_{2}\right)$ are removed from the atmosphere".

According to the USDA Nutrient Database the composition of pecans contains about 3.9g of Carbohydrate per 28 grams. Which pencils out to 139.29 grams of Carbohydrate per kg of pecan kernels. Thus $7.2 \mathrm{~kg}$ of pecan kernels is one kilogram of Carbohydrate or one unit. This means for every $7.2 \mathrm{~kg}$ of pecan kernels $\approx 1.47 \mathrm{~kg}$ of $\mathrm{CO}_{2}$ is sequestered [4].

South Africa produces around 14000 tons of pecans per year. Using an average kernel percentage of $50 \%$, this would be 7,000 tons of pecan kernels. This is 972.222 tons of $\mathrm{CO}_{2}$ that is captured only in the pecan kernels. This could give consumers an incentive to purchase pecans yearly and promote the planting and proper management of pecan groves.

Oxygen $\left(\mathrm{O}_{2}\right)$ production is another major advantage of pecan orchard - that is rarely noticed as a service of plants - which is a by-product of photosynthesis. This is another service rendered by pecan trees in commercial orchards for which there is no real compensation. Managing watersheds and preventing soil erosion is also a benefit of pecan groves, if grass or cover crops are grown between the rows.

Soil management practices plays a determining factor in the thriving or destruction of soil microbiology which also aid in the carbon cycle. Photo 1 demonstrates a conventional pecan orchard with tilled fields in between the rows of pecan trees to keep weeds from consuming moisture in the semi-arid Northern Cape province. Whereas photo 2 shows trees in the North West province that have grass growing between the rows of pecan trees. The difference in growth between the tree rows show the difference in rainfall, between the North West and Northern Cape provinces. 


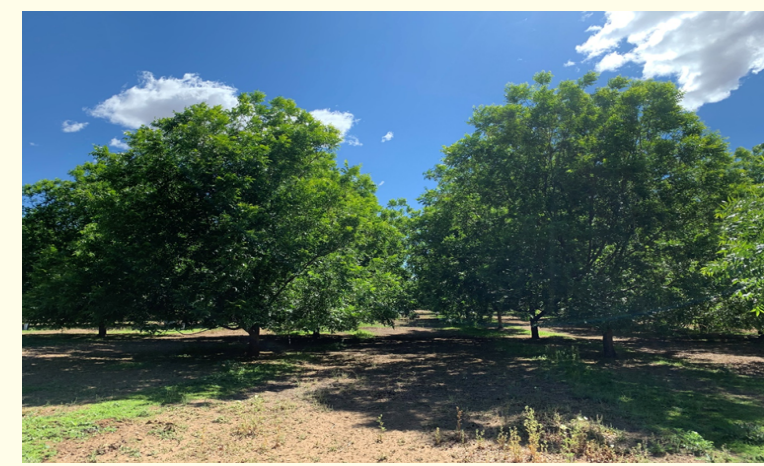

Photo 1

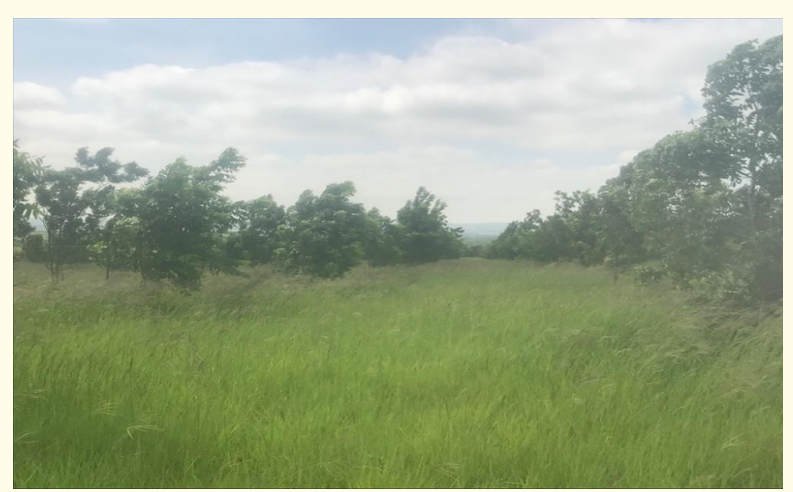

Photo 2

The higher the biodiversity of plants, the greater populations of microbes in the soil, which leads to better carbon sequestration into the topsoil which is then locked within the microbes' bodies. These microbes are not just made up of carbon (C), but of nitrogen (N) too, according to Riya [5]. Managing the carbon-nitrogen ratios of the soil will help keep microbes in a constant growth and improvement of the soil.

One of the biggest benefits of microbes is that when they die off in soil they do not leach readily, which maintains soil fertility and carbon levels in the soil as they are recycled in the soil.

According to Gougoulias, "Soil microbes essentially transfer carbon between environmental compartments to fulfil their fundamental goal: survival through reproduction". Thus, the better the soil conditions for microbial reproduction, the easier carbon can be stored and exchanged in the soil [6].

Roots also find good soil structure a necessity when it comes to moving through the soil. Since roots struggle in compacted soil, which could be due to the compacting effect of equipment, harvest equipment could lead to areas becoming saturated with water and turn anaerobic - due to a lack of drainage. In a study conducted by New Mexico State University's, Kellum, 2018, it was found that in semi-arid Southern New Mexico, soil moisture levels have an impact on the rate that $\mathrm{CO}_{2}, \mathrm{CH}_{4}$, and $\mathrm{N}_{2} \mathrm{O}$ gas exchange occur. It was found that $\mathrm{CO}_{2}$ emissions were highest under field capacity, or at an optimal moisture for aerobic microbes, while $\mathrm{CH}_{4}$ emissions occurred more effectively under saturation - anaerobic soil conditions. Thus, improving soil structure increases $\mathrm{CO}_{2}$ output of microbes under the pecan tree canopy, encouraging the production of biomass within a given year. Kellum [7], concluded that in semi-arid regions $\mathrm{N}_{2} \mathrm{O}$ emissions were the highest after saturation and fertilizer application. Kellum further suggests that anaerobic denitrification is the dominant mechanism of $\mathrm{N}_{2} \mathrm{O}$ emissions in the pecan orchards.

From these conclusions we can see that improper irrigation and fertilizer management can lead to reduction of biomass from aerobic micro-organism reproduction and biodiversity in the soil and an increase in anaerobic micro-organism reproduction and biodiversity. Further from Kellum [7], work it is apparent that aerobic micro-organisms produces additional $\mathrm{CO}_{2}$ that is mainly caught under the pecan tree leaves which increases the speed of biomass production in pecan orchards, there by sequestering more $\mathrm{CO}_{2}$, versus anaerobic micro-organisms, some of which denitrifies soil leading to increased $\mathrm{N}_{2} \mathrm{O}$ and other microbes that emit $\mathrm{CH}_{4}$.

All the microbes, whether aerobic or anaerobic, are competing for resources in the soil and competition is fierce in the rhizosphere where there is continuous flow of carbon-containing compounds from roots to soil, as is stated by Gougoulias. This puts all these microbes in alternating states of population explosions due to our irrigation schedules in pecan orchards.

Plants use this myriad of carbon-containing compounds they excrete through the roots, either to promote the growth or trade of resources with certain microbes - in order to get nutrients or protection from other harmful microbes. Some microbes produce certain hormones to help with biomass growth - shoot or root growth. Plants can go even further to exude certain compounds, thereby drawing certain needed microbes to the roots, while not alerting others to the presence of these compounds in the rhizosphere.

Many fungi living in pecan groves are not just there to utilize the rhizosphere, but to help with the conversion of biomass to more stable forms of organic matter. Not only do they increase soil organic matter, but they increase soil aeration and structure as well, while increasing roots ability to reach further for nutrients and water. Using mycorrhizal fungi is one of the ways to build resilience into the tree cropping system.

\section{Discussion and Conclusion}

Pecan trees provide many services to our environment in South Africa, by sequestrating $\mathrm{CO}_{2}$ into their biomass, providing a healthy snack, and managing watersheds. To make the most of pecan groves, producers should cultivate as much biomass per year as possible and only through harvesting and losing nuts from the orchard, while keeping the leaves, husks, and any pruning residue in the pecan grove. This will help make the pecan industry in South Africa a carbon sequestration 'sink'. Adding to this carbon 'sink' are the microbes and fungi in the soil. The advantage of microbes to pecan nut trees are undervalued in most production areas in South Africa. Not just for the carbon they sequestrate by replicating themselves in the soil, but the amount of additional biomass that is created by the exchange of carbohydrates and other exudates by plant roots. Managing the soil structure and fertilization in such 
a manner as to keep unnecessary greenhouse gas emissions, such as $\mathrm{N}_{2} \mathrm{O}$ and $\mathrm{CH}_{4}$, while promoting soil conditions and fertilization practices that increase soil building microbes to flourish and provide $\mathrm{CO}_{2}$ to actively growing plants that have the ability to take up the $\mathrm{CO}_{2}$ for use as biomass and going back to the soil as stable carbon root exudates, complexed further by microbiology.

\section{Bibliography}

1. Hartman JR., et al. "Pirone's Tree Maintenance". 7th ed. Oxford Univ. Press, N.Y (2000): 545.

2. Mexal JG., et al. "Noncommensurable Values of the Pecan Industry". Electronic Distribution (2003).

3. Jones C. "Liquid carbon pathway unrecognised". Australian Farm Journal (2008).

4. The composition of pecans from the USDA Nutrient Database.

5. Riya S., et al. "Influence of C/N Ratio on Performance and Microbial Community Structure of Dry-Thermophilic Anaerobic Co-Digestion of Swine Manure and Rice Straw". Journal of Medical and Bioengineering 5.1 (2016).

6. Gougoulias C., et al. "The role of soil microbes in the global carbon cycle: tracking the below-ground microbial processing of plant-derived carbon for manipulating carbon dynamics in agricultural systems". Journal of the Science of Food and Agriculture 94.12 (2014): 2362-2371.

7. Kellum DS., et al. "Greenhouse Gas Emissions from Pecan Orchards in Semiarid Southern New Mexico". HortScience 53.5 (2018): 704-709.

\section{Assets from publication with us}

- Prompt Acknowledgement after receiving the article

- Thorough Double blinded peer review

- Rapid Publication

- Issue of Publication Certificate

- High visibility of your Published work

Website: www.actascientific.com/

Submit Article: www.actascientific.com/submission.php Email us: editor@actascientific.com

Contact us: +919182824667 